\title{
Schon mehr als 2200 Fälle registriert
}

\section{Droht uns eine Masernepidemie?}

zum selben Zeitpunkt. Um die Masern zu eliminieren, sind Durchimpfungsraten von 95\% notwendig. Hiervon sind jedoch vor allem die alten Bundesländer weit entfernt. Schlusslicht ist Bayern, wo nur jedes zweite Kind den vollen Impfschutz erhält.

- Nordrhein-Westfalen erlebt derzeit eine Masernepidemie: 1695 Fälle wurden bisher gemeldet. Dr. Ursel Lindlbauer-Eisenach von der STIKO hält angesichts der katastrophalen Durchimpfungsrate eine bundesweite Ausbreitung für möglich. Im gesamten Bundesgebiet lag die Zahl der Erkrankungen bis August 2006 bei 2214, dreimal so hoch wie im letzten Jahr

\section{Säuglinge besonders gefährdet}

Die Folgen einer Epidemie wären vor allem für Säuglinge, die noch nicht geimpft werden können, gravierend: Hier besteht die Gefahr eines atypischen Verlaufs mit Entwicklung einer sklerosierenden Panenzephalitis, die, so Lindlauer-Eisenach, „unweigerlich zum Tod führt". In Deutschland wer- den jedes Jahr fünf bis zehn solcher Fälle registriert.

\section{Jugendliche nach Impfschutz fragen! Aber auch Jugendliche und Erwachse- ne ohne Impfschutz erkranken teilwei- se schwer. Lindlbauer: „Während der aktuellen Epidemie mussten 15\% der Erkrankten hospitalisiert werden. " Vor allem Jugendliche seien eine Alters- gruppe, „an die wir schlecht heran- kommen“. Jeder Arztkontakt eines Ju- gendlichen müsse daher zur Impfung genutzt werden. \\ $\mathrm{EO}=$}

- Pressekonferenz der Bayerischen Gesellschaft für Immun-, Tropenmedizin und Impfwesen e. V., München, 20. 9. 2006

\section{Drei Fragen zur HPV-Vakzine}

\section{Wie gut ist der Impfschutz gegen das Zervixkarzinom?}

MMW: Wie wird sich die HPV-Impfung auf die Inzidenz des Zervixkarzinoms auswirken?

Kimmig: Die HPV-Typen 16 und 18 sind mit ca. $70 \%$ der Zervixkarzinome assoziiert. Bei den übrigen Zervixkarzinomen werden andere HPV-Subtypen nachgewiesen. Die Impfung ist hocheffektiv gegen die Virustypen 16 und 18. Aber es besteht auch die Möglichkeit eines Virus-Shifts hin zu den nicht durch die Impfung erfassten HPV-Subtypen. Außerdem ist die Frage nach der Dauer der Immunität noch nicht definitiv geklärt. Insofern ist eine genaue Beurteilung der Risikoreduktion nicht möglich. Nach meiner Einschätzung dürfte sie aber in einer Größenordnung von ca. $50 \%$ liegen.

MMW: Das heißt, um Vorsorgeuntersuchungen kommt man trotzdem nicht herum?

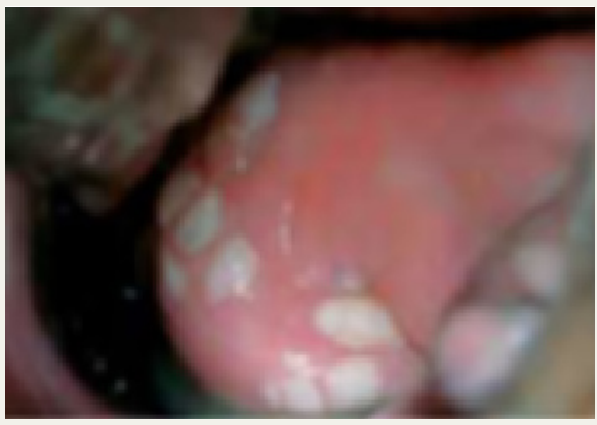

4 Etwa $70 \%$ aller Zervixkarzinome sind durch die humanen Papillomaviren (HPV) 16 und 18 verursacht.
Kimmig: Durch die Impfung mit der tetravalenten Vakzine lassen sich die durch die HPV-Subtypen 6, 11, 16 und 18 induzierten Veränderungen zu einem großen Teil verhindern. Hierdurch kommt es sowohl zu einem deutlichen Rückgang an Genitalwarzen (Kondylomen), wie insbeson-

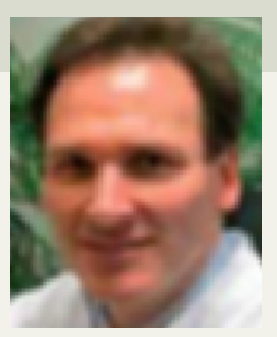

Univ.-Prof. Dr. med. R. Kimmig, Essen dere auch an Präneoplasien und Zervixkarzinomen. Trotzdem ist die Vorsorgeuntersuchung weiterhin erforderlich, da auch bei flächendeckender Impfung die Inzidenz der Erkrankung nur langsam zurückgehen wird. Außerdem haben auch die Geimpften weiterhin ein Risiko, Präneoplasien oder ein Zervixkarzinom insbesondere infolge von Infektionen mit nicht durch die Impfung erfassten Virussubtypen zu entwickeln.

MMW: Wann soll geimpft werden? Kimmig: Um den höchstmöglichen Schutz zu erreichen, ist es erforderlich, die Impfung bei Mädchen vor dem Erstkontakt mit den Viren durchzuführen, also vor Aufnahme der sexuellen Aktivität. Eine raschere Reduktion der HPV-Inzidenz wäre durch eine gleichzeitige Impfung der Jungen zu erreichen. Aufgrund der geringen Rate von HPV-assoziierten Karzinomen bei Männern zweifle ich jedoch, inwieweit die Impfung hier Akzeptanz finden wird.
$\mathrm{EH}=$ 